\title{
A forma dos desejos. A idéia de literatura de Calvino
}

\author{
Mario Barenghi
}

Desire is a wonderful telescope.

(R.L.S.)

Sempre que Calvino se empenha em definir a literatura, ele se detém sobre seus limites. Isso poderia parecer óbvio: toda definição exige a indicação de limites; definir significa (etimologicamente) traçar os confins. Todavia, a tais confins Calvino parece atribuir uma especial importância. Dito um pouco grosseiramente, numa primeira aproximação seria possível dizer que para Calvino a definição de literatura é essencialmente uma questão de fronteira - ou melhor, no plural, de fronteiras.

Calvino tem uma idéia não totalizante da literatura. A literatura para ele não envolve a totalidade da realidade e da experiência. Ainda que autônoma (no sentido de ter regras próprias), não é auto-suficiente, nem se cumpre em si própria. Seguramente pode interessar o agrupamento de elementos do saber: ao menos a partir da metade dos anos 60, Calvino cultiva uma noção epistemológica de literatura, como "mapa do conhecimento". Mas a epistemologia, no momento exato em que reflete sobre princípios e métodos da experiência (ou conhecimento), implica o retorno a um momento posterior (ou precedente), à dimensão concreta do conhecer.

Para Calvino, a literatura se coloca como algo intrinsecamente parcial, que só adquire sentido enquanto consciente de sua própria parcialidade: algo que tem significado e valor enquanto não cessa de confrontar-se com aquilo que não é. As coisas que a literatura pode ensinar são poucas, mas insubstituíveis, recita o fundamental ensaio de 1955, Il Midolo del Leone (não por acaso colocado como abertura de Una Pietra Sopra). Insubstituíveis, sim: mas poucas. O resto é necessário ir aprender em outro lugar, "da ciência, da história, da vida" 2 . Bref, a literatura não deve perder - nem por um instante - os próprios limites.

Partindo desse ponto de vista, o título da conferência que Calvino proferiu aqui mesmo na New York University, há aproximadamente 16 anos, é absolutamente exemplar: Mondo Scrito e Mondo non Scrito (James Lecture, 30 de março de 1983). Como se pode intuir, no centro daquela intervenção está a relação entre linguagem e realidade, e cabe à literatura a tarefa de renovar constantemente essa relação. De que modo? A resposta dada por Calvino não tem a ambição de valer como um princípio absoluto, pois estamos no plano das declarações de poética, muito mais do que no das avaliações estéticas gerais. A questão levantada incide, seja negativamente ou positivamente, sobre a fronteira entre os dois mundos, ou seja, sobre a dificuldade de reencontrar o limiar do mundo não escrito, numa época em que a percepção da realidade aparece colonizada (desfigurada, ofuscada, oculta) pelas palavras. Incide sobre a necessidade (e o propósito) de fugir ao que já foi dito, ao que 
já se sabe, de escrever a respeito daquilo que ainda não se sabe, para tornar possível que o mundo não escrito se exprima através da escritura ${ }^{3}$. Portanto, o campo de ação da literatura é o mundo a escrever: justamente a fronteira. A literatura deve projetar-se além do já explorado, do já adquirido. De resto, o escritor Silas Flanery, alter ego de Calvino em Se Una Note d'Inverno un Viaggiatore, já anotava em seu diário:

... eu não creio que a totalidade possa ser contida na linguagem; o meu problema é o que resta fora, o não escrito, o "não-escrevível"4

Mas a conferência de 1983 traz um outro argumento precioso para nós: a escritura, diz Calvino - assim como a ação da fábula, poderíamos acrescentar - nasce da ausência de algo.

... em minha experiência o impulso de escrever está sempre ligado à falta de algo que gostaria de conhecer e possuir, algo que me escapa. E conhecendo bem esse impulso ele me parece reconhecível também nos grandes escritores, cujas vozes parecem erguer-se do alto de uma experiência absoluta. Aquilo que eles nos transmitem é o sentido da aproximação da experiência, mais do que o sentido de experiência alcançada; o segredo deles é saber conservar intacta a força do desejo. ${ }^{5}$

Conservar intacta a força do desejo. Seria possível, a essa altura, recordar a importância crucial atribuída por Calvino aos inícios, e, no plano textual, aos incipit, que culmina, mas não se exaure, no projeto de Se Una Notte d'Inverno un Viaggiatore. Mas, por se tratar de um argumento a todos familiar, me limitarei a citar um trecho pouco conhecido, retirado dos esboços da Norton Lectures: um trecho da lição inédita (e publicada só dez anos depois da morte do autor) intitulada Del Cominciare e del Finire. Aqui Calvino define o início - exatamente como passagem do mundo das coisas ao mundo das palavras, do mundo vivido ou "vivível" ao mundo verbal - em suma, do mundo escrito ao mundo não escrito - como "o lugar literário por excelência":

O início é o lugar literário por excelência porque o mundo de fora é, por definição, contínuo, não tem limites visíveis. Estudar as zonas de fronteira da obra literária é observar os modos pelos quais a operação literária comporta reflexões que vão além da literatura, mas que só a literatura pode exprimir. ${ }^{6}$

O desejo não parece ser um conceito particularmente adequado a Calvino. Ao contrário, de imediato recorda estilos de pensamento e perspectivas intelectuais muito distantes dele - basta pensar em Lacan. E, de qualquer modo, "desejo" é uma palavra que se deve usar com cautela; com um "amortecedor", como se costuma dizer. Por exemplo, com o amortecimento de uma citação de Robert Stevenson: "O desejo é um magnífico telescópio".

Naquela espécie de enciclopédia do imaginário calviniano, que são Le Città Invisibili, o impulso rumo à felicidade é, por assim dizer, a célula que gera o livro. Basta ler as primeiras páginas colocadas sob o subtítulo "Le città e la memoria": memória sim, mas sempre em função da felicidade sonhada ou perdida (ou inventada, ou lamentada). E logo depois de "Le città e la memoria" segue o subtítulo "Le città e il desiderio". Seria possível, 
entre parêntesis, refletir exclusivamente sobre as rubricas, baseando-se em materiais autográficos (dos esboços preparatórios, dos planos de trabalho), ou reconstruindo certas alusões esparsas no texto. Peculiarmente, o índice dos volumes não registra nem as cidades felizes nem as infelizes, nem as justas nem as injustas: categoria que Marco Polo evoca em momentos cruciais do livro. De resto, a gênese de Le Città Invisibili se mistura aos trabalhos a respeito de Fourier, e a ambição pela felicidade - a reivindicação do direito à felicidade, a legitimação dos desejos, a coincidência entre felicidade e justiça - são os propulsores de toda a utopia.

Como se sabe, há uma tensão utópica que perpassa grande parte da obra calviniana, não apenas naqueles anos. Com relação a isso, La spirale - último conto da primeira série cosmicômica - merece ao menos um aceno. Evocando suas memórias de molusco primordial, Qfwfq explica como um desejo teria precedido, e portando gerado, tanto o impulso à ação, quanto a possibilidade de ver o resultado daquela ação inicial: é de um "sofrimento" inicial - indefinido, inconsciente - que nascem, em ordem, a vontade de fazer algo, a secreção calcária, a forma da pequena concha e o aparelho da visão que perceberá as imagens. Notabilíssimo, entre parêntesis, o julgamento que Calvino expressa a respeito desse conto, em uma entrevista de dezembro de 1965:

"Eu o considero o ponto de chegada daquilo que eu queria fazer com Le Cosmicomiche, mas também um ponto de partida, porque é desse ponto que devo recomeçar a trabalhar".7

A "força do desejo", portanto, converte-se no desejo da forma, ou melhor, em desejo de forma. E, pontualmente, numa espécie de "círculo virtuoso" (de virtuosa espiral?), as Città Invisibili registram a paisagem que sucede esse quadro: não só a força do desejo, mas a força dos desejos. Tal é o privilégio de Zenóbia, a segunda das cidades delgadas (sendo inútil perguntar se deve ser classificada entre as cidades felizes ou entre as infelizes). Num mundo onde freqüentemente, à medida que os anos passam, as cidades acabam cancelando os desejos ou sendo elas próprias canceladas, Zenóbia consegue conservar no tempo a forma dos desejos: ou, ao contrário, dar aos desejos sua própria forma. Assim, quando se pede a um habitante de Zenóbia que descreva a cidade feliz, ele apenas combina de modo variado os elementos constitutivos de Zenóbia.

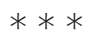

Seria fácil aproximar da conferência de 1983 outros ensaios ou intervenções que tratam do tema dos limites. A discussão sobre a natureza do discurso literário sempre gravita em torno de uma antinomia. $\mathrm{O}$ alvo se encontra numa relação, num ponto de descontinuidade e de oposição. Exemplo disso é in Per chi si Scrive? (subtítulo: Lo scaffale ipotetico), de 1967, cujo tema é a relação não entre escritura e realidade, mas entre a literatura e os livros não literários:

A operação de um escritor é muito mais relevante quanto a estante sobre a qual gostaria de concentrar-se é uma estante ainda improvável, com livros que não costumam ser postos lado a lado e de cujo contato podem surgir fagulhas elétricas, curtos circuitos... uma situação literária começa a ser interessante quando se escrevem romances para pessoas que não são 
leitoras de romances, quando se escreve literatura pensando numa estante de livros não só de literatura. ${ }^{8}$

Num ensaio de 1969, dedicado a Anatomy of Criticism de Northrop Frye (título, a propósito: La Letteratura come Proiezione del Desiderio) Calvino fala de um outro limite: aquele existente entre livros canônicos e não canônicos, ou seja, entre o centro e a periferia de uma biblioteca.

A biblioteca ideal à qual me inclino é aquela que gravita em direção ao "fora", em direção aos livros apócrifos, no sentido etimológico da palavra, isto é, os livros "escondidos". A literatura é a busca do livro longínquo e escondido, que muda o valor dos livros conhecidos, é tensão rumo ao novo texto apócrifo a reencontrar ou a inventar. ${ }^{9}$

Não é necessário recordar que à categoria do "escondido" Calvino dedica a última das rubricas das Città Invisibili. "Escondidas" são as cidades que conservam ao menos uma potencialidade positiva em oposição à grande quantidade de cidades contínuas. E a insistência sobre limites, sobre confins, sobre o "fora", não deixa de interessar ao sujeito que escreve. A respeito disso seria possível citar muitas páginas ensaísticas, mas talvez as mais eloqüentes sejam aquelas nas quais Silas Flanery lamenta não poder desaparecer, reduzindo-se a uma pena que escreve:

Como eu escreveria bem se não existisse! Se entre a folha branca e a ebulição das palavras da história que tomam forma e se esvaem sem que ninguém as escreva não se metesse este incômodo diafragma que é minha pessoa! $!^{10}$

Com Se Una Notte d'Inverno, Calvino realiza o propósito de colocar-se como narrador "anônimo, plural e coletivo" (Belpoliti). Entretanto, exatamente durante os anos 1970, durante a gestação de Se Una Notte d'Inverno, Calvino trabalha em múltiplos projetos autobiográficos. É como se uma vez virtualmente "saído para fora" de si, é possível também falar de si. Estamos diante de uma espécie de poética do estranhamento - um estranhamento programático mas ainda definido, móvel, aberto a bruscas mudanças de tendência. É o "colocar-se sempre do lado de fora", formulado no ensaio Lo Sguardo dell'Archeologo", que exige antes de tudo a capacidade de sair de si, da noção corrente de realidade, dos conhecimentos presumidos.

Mas por quais motivos o horizonte mental de Calvino é dominado pelos confins, pelos limites? Apesar de poderem ser invocadas muitas razões diferentes, a meu ver as principais são duas, uma espacial (ou geográfica), e uma histórica. A razão espacial é constituída pela sua identidade ligure, a respeito da qual Calvino insistiu pontualmente. Difícil subestimar a importância de textos como La Strada di San Giovanni (1962), e, sobretudo, Dall'Opaco (1971). Dall'Opaco, um verdadeiro tour de force de inteligência visual e acuidade analítica, reconstrói as coordenadas mentais originais do autor - as formas primordiais de sua concepção de mundo -, as quais foram determinadas pelos caracteres da paisagem na qual cresceu, ou seja, na Riviera Ligure, uma região costeira densamente habitada, mas confinada entre o mar e um aclive, estendido ao longo das encostas das montanhas. Tal paisagem - e como conseqüência a percepção espacial de Calvino - é contrastada, na refinada abstração topográfica de Dall'Opaco, desde um predomínio das 
linhas sobre as superfícies e das superfícies sobre os volumes, até a virtual redução do espaço a apenas duas dimensões. Uma paisagem feita de margens, muretas, cumes, contrapostos à uniformidade remota do horizonte marinho, isto é, percursos, contornos, perspectivas, mais do que áreas, extensões, volumetrias e, portanto, exclusões, separações, mais do que acúmulos ou fusões. A atenção de Calvino às antinomias entre contínuo e discreto traz origens provenientes dessa oposição primária entre a extensão imensa e estranha do mar e a familiaridade com as linhas fragmentadas, os perfis talhados irregularmente, a aspereza da terra habitada.

Quanto à razão histórica, essa consiste obviamente no fato de que a maturidade de Calvino se dá durante os anos da Segunda Guerra Mundial, com a experiência de guerra como partisan. Da participação naqueles acontecimentos, Calvino extrai a idéia de que também o tempo é algo de substancialmente descontínuo. Na realidade, verificam-se eventos que discriminam nitidamente um antes de um depois, e sobrevem a necessidade de tomar decisões não revogáveis, que condicionam a formação de uma identidade individual. (Seria possível acrescentar que a geração à qual pertenço - aquela dos baby-boomers que completaram vinte anos nos anos 70 - não teve, de fato, em nível coletivo, uma experiência semelhante; talvez ela tenha vivido justamente a experiência contrária).

Além das considerações políticas, a experiência da Resistência marca para Calvino a descoberta de quanto de valor podem ter as ausências. A sua identidade enriquece no exato momento em que renuncia a parte daquilo que era, até aquele instante, sua vida. A privação se transforma em potência. Trata-se, para usar uma metáfora vegetal, de uma espécie de poda. E isso, de experiência biográfica, se transformará em princípio estético: o princípio da seleção, da estilização redutora. Na época das Norton Lectures (1985), Calvino insistirá sobre a imagem da leveza: segundo ele, sua operação foi muitas vezes uma subtração de peso (dos temas, das estruturas narrativas, da linguagem). Mas talvez seja possível aproximar dessa uma outra imagem: Calvino tem substancialmente uma idéia agronômica da literatura. Para que a planta cresça é necessário cortar, eliminar o supérfluo: podar, justamente. Redesenhar os perfis, renovar as margens.

Não creio ser necessário insistir nesse aspecto; bastará dar um exemplo rápido. Todas as personagens de Calvino, não somente os heróis da trilogia cavalheiresca, são o resultado de uma mutilação estratégica. O que é afinal Palomar senão uma figura humana reduzida aos órgãos da vista e do pensamento? Mais do que cortar sua personagem ao meio, Calvino a reduz ao aparato ótico-neurológico (do mesmo modo, Marco Polo contava de cidades feitas apenas de instalações hidráulicas. E o que é Qfwfq, além de um ser humano descontextualizado, subtraído de toda determinação de tempo e espaço? Mais do que exilar o protagonista sobre as árvores, Calvino o submete a um deslocamento "hiperbolicamente" ubíquo. E poderemos continuar, citando não só os projetos interrompidos - como o fragmento La Decapitazione dei Capi (1969) -, mas também projetos em curso e já em grande parte realizados (os contos sobre os cinco sentidos), com a suspeita que depois de ter descrito nossos antepassados, Calvino estivesse descrevendo nossos descendentes.

Uma visão "discreta" do mundo, feita de limites e confins. A eliminação do peso como modo de operação: a poética da estilização do estranhamento, da redução calculada. Seleção e distanciamento, redução e focalização. A obra de Calvino obedece a uma norma 
constitutiva que poderíamos definir, em termos retóricos (ou meta-retóricos) como o desenvolvimento irônico de uma sinédoque. Um desenvolvimento que poderá ter forma de percursio (um proceder rápido na direção da conclusão), de interpretatio (uma ordenada e ramificada dedução de conseqüências) ou de corretio (um obstinado retardamento analítico ou definidor). Nem sempre a rapidez se conjuga à exatidão: depende das circunstâncias, dos tempos. Assim, em épocas diferentes, a predominância do visual pode ser identificada com a mira do caçador ou com o olhar do arqueólogo (envelhecendo, o explorador se torna cartógrafo, colecionador). E do desejo procurará valorizar, ora a força, ora a forma: o impulso dinâmico que acompanha no conto a energia latente na história ou abstração mental que resvala o caos viscoso do presente (o labirinto, o mar de objetividade, a prisão do castelo de If). Mas o que importa é conservar a capacidade de desejar: o sentido da falta como estímulo, a limitação direcionada com impulso produtivo.

Não é só, portanto, a renúncia aproximativa prejudicial à totalidade, mas a concessão da exigüidade, da parcialidade como dado objetivo e, junto como um método de trabalho, uma estratégia de composição. E aqui seria possível arriscar qualquer consideração mais geral. Muitos estudiosos falaram, a propósito de Calvino, em classicismo ou classicidade, ou mais exatamente (Bonsaver) de uma convergência de classicismo e experimentalismo. Essa avaliação parece-me a mais correta, mas gostaria de precisá-la. Clássico ou classicista é a postura de fundo de Calvino: a opção - precoce e jamais colocada em dúvida - por procedimentos formais de tipo seletivo, redutor e orientação (sempre mais clara com o passar dos anos) a transformar os limites em sistema de operação ou, mais exatamente em regras, às quais não corresponde nenhum dado ontológico ou natural: trata-se simplesmente de escolhas convencionais, axiomáticas, em geral ostensivamente bizarras e arbitrárias. É útil, a esse respeito, a noção de contrainte sobre a qual se funda a ação do grupo parisiense do Oulipo (Ouvroir de Littérature Potentielle), no qual Calvino entra convidado por Queneau, em 1972. A contrainte é exatamente uma regra que o autor se impõe espontaneamente, fora de toda pretensão de verossimilhança, para verificar quais são suas conseqüências, quais mecanismos produz. Portanto, em Calvino é correto falar na coexistência de "classicidade" e experimentalismo. Finalmente, seria possível falar (se é permitido o oxímoro) em uma espécie de classicismo oulipien.

Por certo não há absolutamente nada de "romântico" no modo como Calvino concebe a parcialidade - como uma condição de existência e uma escolha formal privada de traços sentimentais. Não resta nenhuma nostalgia pelo todo, nenhuma Sehnsucht. Muito pelo contrário, o que se vê é uma adesão tenaz a um dado, um tema, um axioma particular, do qual se extrai uma série de deduções. Não que falte em Calvino uma remissão ao infinito - o cósmico é uma dimensão que entra na narrativa calviniana, e se reforça no último período associada a um "(hiper) realismo minimalista e fenomenológico" (MacLaughlin) mas do infinito Calvino não propõe uma visão emotiva. Permanece válido o peremptório tema do Midollo del Leone: "uma relação afetiva com a realidade não nos interessa"12.

$$
* * *
$$

Penso ter em frente, no máximo, uma platéia de admiradores de Calvino: isto é, de leitores e de estudiosos que, amando a sua narrativa, tendem a compartilhar também suas 
reflexões teóricas e suas enunciações programáticas. Todavia, é sempre útil confronta-se com quem tem julgamentos e gostos diferentes. Mencionarei o ensaio de um dos mais hábeis críticos italianos da atualidade, Alfonso Berardinelli. Trata-se de Calvino Moralista, ovvero Come Restare Sani Dopo la Fine del Mondo, publicado em 1991, em Diario, uma revista refinada mas pouco difundida.

Nessa sua intervenção, Berardinelli diz algumas coisas inexatas, algumas agudas e apropriadas, outras infundadas e inaceitáveis, mas sobretudo, para além das meras afirmações, troca de sinal alguns pressupostos básicos da crítica calviniana - julgamentos tão consolidados quanto legitimados pelas análises autocríticas do escritor.

Assim, a insistência sobre os limites, a adesão a perspectivas parciais, as contraintes, em suma, todos os procedimento de seleção, redução, distanciamento e focalização que a obra de Calvino coloca em cena, são envolvidos por uma suspeita, ou melhor, por uma objeção de fundo. Calvino, afirma Berardinelli, peca por excesso de prudência e de cálculo. Se ele desconfia do "eu", escondendo e dissimulando a própria personalidade, é porque tem medo de se expor. Se muda com freqüência o estilo, ou registro, ou o modo de escrever, é porque não quer se arriscar, quer se assegurar de um ponto de fuga. O seu amor à leveza e à clareza racional nasce do desejo inconfesso de evitar o drama: são astutos expedientes que visam a excluir o drama da representação literária. Em uma palavra, se Calvino mantém bem distintas literatura e realidade, é para defender-se da própria realidade - e não para compreendê-la melhor, como gostaria de fazer crer. Há algum tempo, a propósito do Barone Rampante, Cesare Cases havia falado de pathos da distância, e Berardinelli, corrigindo essa fórmula crítica, insinua que o pathos da distância pode transformar-se em comfort da distância. Não a distância do olhar que perscruta, da razão que indaga, mas, mais banalmente, a distância da segurança de quem não quer correr riscos; boa para quem viaja de automóvel, não necessariamente para quem escreve contos.

Como rebater esses argumentos? Com uma premissa, antes de mais nada. Segundo penso, a imagem de Calvino descrita por Berardinelli é deformada, mas não absurda. É possível ler Calvino objetivamente daquele modo. Muitos, como pressuponho, o fazem. Quantos não terão lido Manzoni como um bonachão, satisfeito com sua sabedoria pessoal e sensata? É o destino dos grandes autores: sua grandeza e sua fama (em gíria midiática se diria: sua grande visibilidade) os condena ao mal-entendimento. Assim, se lermos Calvino de uma certa maneira, é possível fazer dele uma hábil e sedutor calculista, que finge falar do mundo quando, na verdade, está jogando com as palavras e com as imagens, nos divertindo, e, no entanto, faz passar por absorto e problemático um comportamento evasivo e voluntarista. Mas essa interpretação não me parece correta.

Entre tantas razões pelas quais a literatura não é auto-suficiente - não se satisfaz consigo mesma, não é voltada para si própria - está a necessidade da cooperação do leitor. Nenhum escritor contemporâneo refletiu por tanto tempo e de maneira tão produtiva como Calvino sobre o papel do leitor. Ora, o leitor sobre o qual Calvino pensa é um leitor ativo, responsável e idealmente superior ao próprio escritor (talvez, parafraseando um notável passo da poética aristotélica, seria possível classificar a obra literária em função do nível do leitor implícito, que pode ser suposto pelo escritor como igual, melhor ou pior a si próprio). Memoráveis são as palavras do já citado ensaio Perché Si Scrive?: 
A literatura deve pressupor um público culto, mais culto do que o próprio escritor, se esse público existe ou não, não importa. O escritor fala para um público que sabe mais do que ele; se faz passar por alguém que sabe mais do que ele sabe, para falar com alguém que sabe mais ainda. A literatura tem que jogar muito alto, apostar nas alturas, cobrir o último lance. ${ }^{13}$

A rigor, podemos considerar que essa afirmação - e, em definitivo, toda a reflexão de Calvino sobre a prática da leitura e sobre a função do leitor - como uma ficção no sentido mais comum da palavra. Como um clichê. Mas à parte o fato de que quando Calvino disse essas coisas, o argumento estava bem longe de ser assimilado pelo debate crítico, já que se estava sob a luz dos estudos sobre a recepção, procedendo assim nós reduziremos Calvino a um escritor insignificante (juízo que Berardinelli não compartilha): seria um escritor que não conseguiria “entrar" no próximo milênio nem mesmo para denegri-lo. A verdade é que nos cabe escolher, decidir que uso fazer daquilo que lemos (e não há coisa boa, observava Huet há cerca de três séculos, da qual não se possa fazer um mal uso). Cabe a nós, portanto, tomar a sério ou não esse apelo à responsabilidade - ou "coresponsabilidade" - do leitor. E Calvino era plenamente consciente disto. Refletindo sobre a narrativa como processo combinatório, o ensaio central de Una Pietra Sopra (Cibernetica e Fantasmi, 1967) expõe o dilema com extrema lucidez:

O jogo pode funcionar como desafio de compreensão do mundo ou como dissuasão de compreendê-lo; a literatura pode trabalhar tanto no sentido crítico quanto na conformação com as coisas tais quais elas são. O limite não é sempre assinalado claramente. Direi que nesse ponto o posicionamento diante da leitura se torna decisivo. Compete ao leitor fazer com que a literatura explicite sua força crítica, e isso pode acontecer independentemente da intenção do autor. ${ }^{14}$

Estou quase por concluir. Calvino, especialmente nos últimos anos de sua vida, não olhava com otimismo o mundo à sua volta. Basta ler o prefácio de Una Pietra Sopra (a sociedade como fracasso, gangrena, colapso, ou no máximo, a vida um dia após o outro); o Mondo Scritto e Mondo Non Scritto, com as suas amargas constatações sobre a peste que se abateu sobre a linguagem, exatamente quando toda a realidade parece já dita antes que seja avaliada. No entanto, quando lemos e relemos as páginas de Calvino temos uma outra impressão. Para mim, ao menos, acontece assim. Quando o releio tenho a sensação de que, se também a realidade da qual ele fala é labirinto, entropia, catástrofe, o modo como ele dialoga com o leitor não é nunca nem caótico, nem labiríntico, nem entrópico ou catastrófico. E isso se deve ao fato de a realidade ser feita também de diálogos - de comunicações, de relações: de relações interpessoais, para usar uma expressão um pouco pretensiosa - ler Calvino para mim significa (mas espero que não só para mim) sentir-me frente a frente com esse mundo não escrito, tão insensato, emaranhado e enigmático, tão difícil de interpretar, de uma maneira um pouco menos vulnerável.

\section{Notas}

1 I. Calvino, Una Pietra Sopra, Torino, Einaudi, 1980, p.187 e Saggi 1945-1985, (a c. di M. Barenghi), Milano, Mondadori, 1995, p.233. 
2 I. Calvino, Una Pietra..., p.14 e Saggi..., p. 22.

3 I. Calvino, Saggi..., p.1875.

4 I. Calvino, Romanzi e Racconti, vol. II, Milano, Meridiani Mondadori, 1992, pp. 789-790.

5 I. Calvino, Saggi..., p.1874.

6 I.Calvino, Saggi..., p. 735.

7 I. Calvino, Romanzi e Racconti, vol. II ..., p. 1344.

8 I. Calvino, Una Pietra..., pp.159-160 e Saggi..., p. 200.

9 I. Calvino, Una Pietra..., p. 203 e Saggi..., p. 251.

10 I.Calvino, Romanæi e Racconti, vol. II ..., p.779.

11 I. Calvino, Una Pietra...p. 269 e Saggi..., p. 365.

12 I. Calvino, Una Pietra..., p. 14 e Saggi ..., p.22.

13 I. Calvino, Una Pietra..., p. 162 e Saggi ..., p.202.

14 I. Calvino, "Cibernetica e fantasmi” in Una Pietra..., p.180 e Saggi..., p. 224. 